\title{
Das Ende der deutschen Barockoper
}

Hat sich die frühdeutsche Oper geographisch wie gesellschaftlich, literarisch wie musikalisch, nicht zuletzt noch unter dem Einfluß des Dreißigjährigen Krieges aus chaotischen Anfängen heraus entwickelt und war es ihr gelungen, in der letzten Generation um die Jahrhundertwende in Hamburg eine angemessene Heimstatt zu finden, so verlor sie diese genau so unerwartet, wie sie sie gefunden hatte. Sicherlich gibt es für dieses plötzliche „Ende“ hier und in anderen ihrer Stützpunkte viele Gründe, vor allem die von Johann Christoph Gottsched mit Verve vertretene rationalistische Einstellung, aufgrund derer er die Oper als Inbegriff der Unnatur bekämpfte. Dem widerspricht allerdings die Tatsache, daß in Hamburg auch nach der Schließung des Opernhauses (1738) Opern aufgeführt worden sind, nun allerdings, durch die Mingottische Operntruppe, italienische. Hier zeigt sich also doch wieder die Neigung zu dem alten Vorbild, wo nicht sogar dessen Sieg, der sich unübersehbar durch den abrupten Abgang des jungen Händel 1706 nach Italien bereits angekündigt hatte. Außerdem waren ja auch die italienische wie die französische Oper in jener Zeit nicht minder Ziele von gleichgerichteten Angriffen gewesen, ohne daß sie davon entscheidend berührt, geschweige denn vernichtet worden wären. Das wäre bei den organisch und allmählich aus dem Boden der heimischen Kulturen erwachsenen Gattungen auch kaum denkbar gewesen. Das Produkt eines zunächst gleichsam abenteuerlustigen Experimentierens hingegen fiel trotz bedeutender Leistungen letztlich allen Anwürfen als relativ leichte Beute zum Opfer, zumal es, wie das Hamburger Beispiel zeigt, vom Publikum ohne weiteres verschmerzt wurde. So kam es, daß sich die deutsche Oper nicht nur in ihren Anfängen den anderen gegenüber im Nachteil befunden hatte, sondern daß ihre Entwicklung trotz des durch Meister wie Keiser und Telemann erreichten hohen Niveaus aufgrund der in ihr verborgenen Zwiespältigkeit dort, wo ihre ausländischen Schwestergattungen den Epochenwandel wiederum organisch und allmählich überwanden, als deutsche Barockoper brüsk abbrach, und erst nach geraumer Zeit das zaghafte Ringen um eine "teutsche Opera“ unter ganz anderen Umständen völlig von neuem begann.

\section{Das deutsche Singspiel}

Das abrupte Ende der „frühdeutschen Oper“ bedeutete ausschließlich das Verschwinden einer nicht mehr zeitgemäßen Gattung - die Opernpflege in Deutschland wurde davon nicht berührt, schon gar nicht an den größeren Höfen, die nach wie vor fest in italienischer Hand waren, aber auch ebensowenig im Bereich der Wandertruppen, die im 18. Jahrhundert mehr und mehr auch für die Oper an Bedeutung gewannen.

Die Lücke von ca. 30 Jahren in der deutschen Opernproduktion, die jetzt entstand, wirkte sich daher unter der gleichförmig italianisierten Oberfläche der Opernpflege in erster Linie nur als Generationswechsel aus. Dabei war das Ziel der neuen Generation, wie das der alten, die „deutsche Oper", nur verfolgte sie es, ohne auf jene Bestrebungen zurückzublicken, wiederum zeitbedingt auf ganz anderen Wegen, allerdings, schicksalhaft für alle jene deutschen Bemühungen um die ersehnte Gattung, auch sie im Anschluß an fremde Vorbilder. Während aber die frühdeutsche Oper grundsätzlich dem anspruchsvollen Beispiel der durchkomponierten alten Gattungen Italiens und Frankreichs gefolgt war, hielt sich die neue Generation an die junge Gattung der opéra comique, 